\title{
The Impact of Heat and Vibration on the Density of Root Filings Produced by Lateral Compaction: A Comparative Study on Artificial Blocks and Natural Teeth
}

\author{
I Abramovitz ${ }^{1}$, T Prokocimer ${ }^{1}$, Z Metzger ${ }^{2}$, D Moreinos ${ }^{1}$, J Moshonov ${ }^{1}$ and ETR Farmakis*3 \\ ${ }^{1}$ Department of Endodontics, The Hebrew University, Israel \\ ${ }^{2}$ Department of Endodontology, Tel Aviv University, Israel
}

${ }^{3}$ Department of Endodontics, National and Kapodistrian University of Athens, Greece

Received: February 24, 2018; Published: March 05, 2018

*Corresponding author: Eleftherios Terry R Farmakis, Department of Endodontics, University of Athens, Greece, Tel: 302106640358; Email: elefarm@dent.uoa.gr

Abstract

Background: Cold lateral condensation due to its simplicity and the high control it offers over the apical gutta-percha placement is among the most popular and widely used methods of root canal filling. One of the main limitations of this technique is that it allows gaps to form, often resulting in a high percentage of sealer along and between the cones, especially in the apical area.

Objective: To evaluate gutta-percha obturations density produced by cold, warm and vibrating-warm lateral compaction techniques in artificial and natural root canals

Methods: Forty acrylic blocks and 40 single-rooted extracted teeth were instrumented using ProTaper® rotary files up to F3. The canals were laterally compacted with gutta-percha, weighed and subjected to warm lateral compaction followed by vibrating-warm lateral compaction. The teeth and blocks were re-weighed following each phase. The added gutta-percha in each phase was compared with the control (cold lateral compaction). The Wilcoxon Signed Ranks test and the Mann-Whitney test were used for statistical analysis.

Results: Warm lateral compaction increased the density of gutta-percha compared to with cold lateral compaction in blocks and root canals by $23.5 \%$ and $25 \%$, respectively ( $p<0.001$ ). Warm and vibrating compaction further increased the gutta-percha's density by $33 \%$ and $53 \%$, respectively $(\mathrm{p}<0.001)$.

Conclusion: Warm lateral compaction combined with the vibrating-warm techniques enhanced the density of gutta-percha filling of root canals, compared with cold lateral compaction alone. The added vibration was more beneficial in root canals of natural teeth than in artificial canals of training blocks.

Keywords: Endodontics; Root canal obturation; Gutta-percha; Lateral condensation; Warm Gutta Percha

\section{Introduction}

Three-dimensional obturation of the root canal system is a hallmark of root filling quality [1]. Gutta-percha is widely used for this purpose because of its biocompatibility, dimensional stability and plasticity when warmed. Various methods of vertical warm compaction have been widely applied and studied [1-4]. Nevertheless, due to its simplicity and the high control it offers over the apical gutta-percha placement, cold lateral compaction is still among the most popular and widely used methods of root filling $[5,6]$. One of the main limitations of this technique is that it allows gaps to form [7], often resulting in a high percentage of sealer along and between the cones, especially in the apical area [8-10]. In case of coronal leakage, bacteria will penetrate through the gaps of obturation and contaminate the pulp space within few weeks' time according to the available literature [11,12]. Additionally, if sealer presents with high solubility or contraction during setting, newly created voids in the mass of the root filling or along the canal wall may form, which, may allow further leakage and provide additional pathways for bacterial penetration $[13,14]$.

Studies that compared cold lateral compaction with thermoplastisized techniques showed that a significant higher 
percentage of the canal was filled with gutta percha when using the warm compaction techniques $[15,16]$. In their work, De Deus et al. showed that when using cold lateral compaction, only $50 \%$ of the canal was filled with gutta percha [15]. Keles et al. showed that when comparing cold lateral compaction with warm vertical compaction the voids in the canals decreased from $4.26 \%$ to $0.57 \%$ respectively [16]. In all studies none of the specimens were void free. From the above reviewed studies it may be concluded that warm compaction technique may increase the gutta-percha mass, on the expense of cement and voids in the canal. On the other hand, cold lateral compaction technique benefits from good apical control [17]. Warm lateral compaction is a modification of the cold lateral technique that benefits from good apical control and the advantage of the thermoplasticity of gutta-percha. This technique may enable compaction of a greater gutta-percha mass, reducing the voids and cement proportions to enhance a better three-dimensional filling of the root canal [18-20].

Warm lateral compaction has proven to produce a homogeneous mass, which in leakage test performed significantly better than cold lateral compaction [21]. The DownPack system (Hu Friedy, Chicago, Il, USA) combines warming the gutta-percha with a vibrating effect, which is claimed to enhance the movement of the softened material $[22,23]$. This device may also be used in combination with warm lateral compaction in a method that may be termed "vibrating-warm lateral compaction". Acrylic training blocks have been widely used to examine the changes in gutta-percha density following different compaction techniques, including the latter one $[18,22,24,25]$. However, no experimental information is available on the influence of vibrating warm lateral compaction when applied in natural root canals compared to the other previously mentioned obturating techniques. The aim of this study was to evaluate the quality of obturation resulting from the three aforementioned techniques by means of density, in either artificial canals of training blocks or natural root canals.

\section{Materials and Methods}

Teeth and Artificial Blocks: Forty maxillary incisors and canines were selected from a random collection of recently extracted teeth that were kept in a $0.5 \%$ thymol solution. Inclusion criteria included teeth with mature apices, with no cracks or caries and with no previous endodontic treatment. The crowns of the teeth were removed and the coronal part of the tooth was reduced by grinding with a diamond-coated high speed bur (Strauss, Raanana, Israel) to adjust all the root canals to a uniform length of $17 \mathrm{~mm}$. Transparent acrylic blocks with simulated $17 \mathrm{~mm}$ root canals $(\mathrm{n}=40)$ were also used (Endo-Training-Blocks, 0.02 Taper, Dentsply-Maillefer, Ballaigues, Switzerland).

Root Canal Preparation: The canals, in natural teeth and simulated training blocks, were instrumented using ProTaper rotary files (Dentsply-Maillefer) which were applied according to the manufacturer's instructions and following the sequence of instruments to F3. Working length was determined $1 \mathrm{~mm}$ short of the apical end of the canal, which was verified with the aid of a \#10 K file. Patency was maintained throughout the procedure by periodically passing a \#10 K file through the apical foramen. The canals were irrigated, after each instrumentation, alternating between $1 \mathrm{ml}$ of $2.5 \%$ sodium hypochlorite and 17\% EDTA, which were applied using a syringe and a $25 \mathrm{G}$ needle. The canals were further instrumented to working length with a size $\# 40 \mathrm{~K}$ file (Dentsply-Maillefer), irrigated and thoroughly dried with paper points. Each tooth or block was then weighed, using an analytical balance with an accuracy of $0.01 \mathrm{mg}$ (XB 120A, Precisa, Switzerland).

Lateral Compaction Procedures: As the purpose of the study was to evaluate, by weighing, the amount of gutta-percha alone in the root canals, no sealer was used in any of the procedures $[18,22,24]$. The study was designed so that each filling produced using cold lateral compaction served as control for the subsequent procedures that were performed in the same canal.

Cold Cateral Compaction: A standardized size 40-45 guttapercha master cone (Dentsply-Maillefer), was placed to working length. Cold lateral compaction was performed, using a nickeltitanium B finger spreader (.04 taper, Dentsply-Maillefer) and No25 gutta-percha accessory cones (Dentsply-Maillefer). The spreader was inserted with apical pressure and a quarter of circular back-and-forth rotational movement, mimicking as far as possible a clinical procedure. The procedure was continued until the canal was completely filled and the finger spreader could no longer be inserted more than $1 \mathrm{~mm}$ into the gutta-percha mass. A hot instrument was then used to remove the excess gutta-percha, so that it became flush with the canal opening. The tooth or block was then re-weighed and the weight of gutta-percha that each canal contained was calculated by subtracting the weight of the empty tooth/block from that of the filled one.

Warm Lateral Compaction: Warm lateral compaction was further applied to the same specimens, using the DownPak system (Hu Friedy) as a heat source. An F plugger tip (size 30 with a .03 taper) was used as a heat source and operated at $220 \mathrm{oC}$. The tip of this heat source was inserted as far apically as clinically feasible for $3 \mathrm{sec}$, and then removed. This was followed by lateral compaction with a finger spreader that was applied as above. Accessory cones were used to complete the obturation, and the excess gutta-percha was removed with a hot instrument, as above. The specimens were then re-weighed and the weight of gutta-percha in the specimen after this additional procedure was calculated as above.

Vibrating-Warm Lateral Compaction: The same heat source was again applied, but this time augmented by vibrations. Lateral compaction was performed as above and excess gutta-percha was removed until it was flush with the canal orifice. Each tooth or block was weighed again and the amount of gutta-percha it contained in its canal after this additional procedure was calculated, as above. The force applied to the finger spreader in all the above procedures was similar to that applied in regular clinical procedures. It was measured in a preliminary experiment and was no greater than 2.5 $\mathrm{kg}$. All procedures were performed by a single operator who was an experienced endodontist. 


\section{Statistical Analysis}

The amount of gutta-percha contained in the canal after the different procedures in the artificial training blocks was compared using the paired t-test. As the results of similar comparisons in natural root canals did not have a normal distribution, their comparison was made using the Wilcox Signed Rank Test. The relative (\%) increase in gutta percha weight in the canals of the artificial blocks and the relative (\%) increase that occurred in the natural canals were compared using the Mann-Wihtney Test. Significance levels were set at $\mathrm{p}<0.05$. SPSS-IBM statistics 19 software was used.

Table 1: Amount of Gutta-Percha Contained in Natural and Artificial Root Canals after Cold Lateral Compaction and After Subsequent Warm Lateral Compaction and Additional vibrating-warm Lateral Compaction (Gutta-Percha Weight in mg).

\begin{tabular}{|c|c|c|c|c|}
\hline \multicolumn{3}{|c|}{ Canals in Training Blocks (n=40) } & \multicolumn{2}{c|}{ Canals in Natural Teeth (N=40) } \\
\hline Cold LC & + Warm LC & + Vib-Warm LC & Cold LC & + Warm LC \\
\hline $63.9( \pm 3.6) \mathrm{a}$ & $78.9( \pm 5.3)$ & $85.2( \pm 4.7)$ & $32.4( \pm 23.2)$ & $40.5( \pm 26.8)$ \\
\hline-- & $+23.5 \% \mathrm{~b}$ & $+8.0 \% \mathrm{c}$ & -- & $+25.0 \% \mathrm{~b}$ \\
\hline-- & -- & $+33.3 \% \mathrm{~d}$ & -- & $+22.5 \% \mathrm{c}$ \\
\hline
\end{tabular}

${ }^{a}$ Weight of gutta-percha in $\mathrm{mg}$

${ }^{\mathrm{b}}$ Percent Increased Weight Compared with Cold Lateral Compaction

c Percent Increased Weight Compared with Cold Lateral Compaction, Followed by Warm Lateral Compaction

d Percent Increased Weight Compared with Cold Lateral Compaction Alone

Training Blocks: The weight of the gutta-percha contained in the simulated root canals, after each stage of the obturation is presented in Table 1. The amount of gutta-percha in the simulated root canals after the warm lateral compaction increased by $23.5 \%$ compared with that recorded after the cold lateral compaction alone ( $p$ < 0.001). An additional application of vibrating-warm lateral compaction further increased that amount by $8 \%$ compared with the first warm lateral compaction $(\mathrm{p}<0.01)$ and by $33 \%$ compared with the cold lateral compaction alone $(\mathrm{p}<0.001)$.

Natural Teeth vs. Training Blocks: A similar relative added value of warm lateral compaction in training blocks and natural teeth was recorded: $+23.5 \%$ and $+25.0 \%$, respectively $(p>0.05$ ). Application of an additional vibrating-warm procedure in natural canals resulted in a total improvement of $+53 \%$ compared with the cold lateral compaction, whereas in the artificial canals of the training blocks a lower total improvement of $+33 \%$ was recorded $(\mathrm{p}<0.001)$.

\section{Discussion}

Sealer is the weak, yet irreplaceable link in the chain to a longlasting successful obturation. The thicker the sealer is, the more leakage is expected, and that may negatively influence the outcome [26]. Thus, most obturation procedures aim at filling as much of the pulp space volume with gutta-percha, and also minimizing the amount of sealer [27]. This may be achieved by the wedging effect of spreaders when performing lateral compaction or by thermoplasticizing the gutta-percha to enhance its flow under vertically applied pressure $[8,10]$. Warm gutta-percha techniques gained popularity, among other reasons, owing to their optimizing the amount of gutta-percha to sealer ratio $[8,9]$. Nevertheless, the difficulty in controlling the apical placement of the softened guttapercha is one of the drawbacks of this technique [2]. The present results indicate that the addition of adding a heat-softening element to a lateral compaction procedure may bring the results closer to the aforementioned goal and that a combination of heat with vibration may further enhance the obturation results. Nevertheless, it goes without saying that in a clinical situation, sealer must be used with all of the techniques. In this work, no sealer was used in order to eliminate influencing factors that would complicate methodological approaches such as standardizing the volume of sealer, as reported by others in the literature $[28,29]$.

The present results are in agreement with previous studies that addressed this issue, in which acrylic training blocks were used to examine the impact of double heat application on the results of lateral compaction. Liewehr reported a $17.06 \%$ total increase in gutta-percha weight following two steps of warm lateral compaction, with a minor added value of $2.43 \%$ upon second heat application [14]. Deitch et al. [24], using a similar model, found a $26.92 \%$ improvement in the density of laterally condensed gutta-percha following the first heat application via an activated ultrasonic file. Additional heat application resulted in an additional $2.43 \%$ increase in gutta-percha weight. Nelson et al. [23], used System B as a heat source to obtain a total $26.52 \%$ improvement in gutta-percha compaction following two steps of heat-assisted lateral compaction in acrylic blocks. In all the above mentioned studies, the added value of the second heat application 
was minor: $2.43 \%$ to $5.95 \%$. All these studies used acrylic training blocks and the results of the present study using acrylic blocks, namely a $23 \%$ improvement with the first application of heat and a limited addition of $8 \%$ in a second heat application, are similar to the previously reported findings. Pagavino et al. [20], who used a heating and vibrating device similar to the one used in the present study, also reported improved gutta-percha to sealer ratio in simulated canals in acrylic blocks.

The main difference between the present study and all previous ones mentioned above is in the use of natural teeth. This was especially evident after the second application of heat and vibration which increased the amount of gutta percha in natural teeth by $22.5 \%$, as compared to improvement by $8.0 \%$ in the artificial canals. Artificial canals in acrylic training blocks are designed to be effortlessly manipulated and filled compared with natural teeth. These artificial canals will commonly have a canal preparation which ends up in a uniform, round, conical and symmetrical shape. Root canals in natural teeth, on the other hand, are different and often have oval cross sections and irregularities [30]. Such anatomy may explain the significantly higher additive effect that was found with vibrating-warm technique in the natural canals in the present study. The heat softening of the gutta-percha, combined with the vibration most probably allowed the gutta-percha to flow into irregularities that were not reached when cold lateral compaction alone was applied, thus increasing the amount of gutta-percha in the same canals by a total of $53 \%$.

It is important to note that this was achieved while using the finger spreader with no excessive force, compared to normal clinical procedure. Such an explanation is consistent with the results of Kulide et al. [30] who have found that warm lateral compaction augmented with vibrations and warm vertically condensed injectable filling techniques were superior to warm vertical techniques or warm lateral techniques without vibration in filling artificial grooves in the canal wall. The present results strongly support

a) The use of natural teeth rather than artificial training blocks in this type of studies and

b) The use of heat source and preferably vibrating heat source to augment a lateral compaction procedure and result in densier-filled root canals. In a future study, it will be of interest to compare the present results with those that may be achieved in natural teeth vs. artificial blocks when using other thermoplasticized gutta-percha methods, such as various vertical compaction methods. It will be also of special interest to test these methods in natural teeth which were intentionally selected for their oval canals.

\section{Conclusion}

Under the limitations of this study, the added heat and vibration resulted in densier obturations. The added vibration was significantly more beneficial in root canals of natural teeth than in artificial canals of training blocks. Natural teeth rather than artificial training blocks should be used when evaluating guttapercha compaction methods.

\section{References}

1. Schilder H (1967) Filling root canals in three dimensions. Dent Clin North Am 11: 723-744.

2. Tagger M, Tamse A, Katz A (1983) Efficacy of apical seal of engine plugger condensed root canal fillings- leakage to dyes. Oral Surg Oral Med Oral Path 53: 641-646.

3. O'Neill KJ, Pitts DL, Harrington GW (1983) Evaluation of the apical seal produced by the McSpadden compactor and the lateral condensation with a chloroform-softened primary cone. J Endod 9: 190-197.

4. Buchanan LS (1996) the continuous wave of obturation technique: centered condensation of warm gutta percha in 12 seconds. Dent Today 15: 1-9.

5. Jenkins SM, Hayes SJ, Dummer PMH (2001) A study of endodontic treatment carried out in dental practice within the UK. Int Endod J 34: 16-22.

6. Whitworth J (2005)Methods of filling root canals: Principles and practices. Endod Topics 12: 2-24.

7. Friedman S, Abitbol S, Lawrence H (2003) Treatment outcome in endodontics: The Toronto Study. Phase 1: initial treatment. J Endod 29: 787-793.

8. Eguchi DS, Peters DD, Hollinger JO, Lorton L (1985) A comparison of the area of the canal space occupied by gutta-percha following four guttapercha obturation techniques using Procosol sealer. J Endod 11: 166175.

9. De Deus GA, Martins F, Lima AC, Gurgel-Filho ED, Maniglia CF, et al. (2003) Analysis of the film thickness of a root canal sealer following three obturation techniques. Pesqui Odontol Bras 17: 119-125.

10. Schafer E, Nelius B, Burklein S (2012) A comparative evaluation of gutta-percha filled areas in curved root canals obturated with different techniques. Clin Oral Investig 16: 225-230.

11. Torabinejad M, Ung B, Kettering JD (1990) In vitro bacterial penetration of coronally unsealed endodontically treated teeth. J Endod 16: 566-569.

12. Khayat A, Lee SJ, Torabinejad M (1993) Human saliva penetration of coronally unsealed obturated root canals. J Endod 19: 458-461.

13. Kazemi RB, Safavi KE, Spangberg LS (1993) Dimensional changes of endodontic sealers. Oral Surg Oral Med Oral Path 76: 766-771.

14. Marin-Bauza GA, Rached-Junior FJ, Souza-Gabriel AE, Sousa-Neto MD, Miranda CE, et al. (2010) Physicochemical properties of methacrylate resin-based root canal sealers. J Endod 36: 1531-1536.

15. De-Deus G, Reis C, Beznos D, de Abranches AM, Coutinho-Filho T, et al. (2008) Limited ability of three commonly used thermoplasticized guttapercha techniques in filling oval-shaped canals. J Endod 34: 1401-1405.

16. Keles A, Alcin H, Kamalak A, Versiani MA (2014) Micro-CT evaluation of root filling quality in oval-shaped canals. Int Endod J 47: 1177-1184.

17. Bergenholtz, Preben Horsted Bindslev, Claes Reit (2009) Textbook of Endodontology, ( $2^{\text {nd }}$ Edition), Wiley pp. 396.

18. Liewehr FR, Kulild JC, Primack PD (1993) Obturation of a C-shaped canal using an improved method of warm lateral condensation. J Endod 19: 474-477.

19. Liewehr FR, Kulild JC, Primack PD (1993) Improved density of guttapercha after warm lateral condensation. J Endod 19: 489-491.

20. Pagavino G, Giachetti L, Nieri M, Guiliani V, Russo DS (2006) The percentage of gutta percha filled area in simulated curved canals when filled using Endo Twin, a new heat source device. Int Endod J 39: 610615. 
21. Kersten HW (1988) Evaluation of three thermoplasticized gutta-percha filling techniques using a leakage model in vitro. Int Endod J 21: 353360 .

22. Cohen S, Berman LH (2008) Obturation with heat and vibration: The DownPak Device. Gen Dent 56: 194-196.

23. Nelson EA, Liewehr FR, West LA (2000) Increased density of guttapercha using a controlled heat instrument with lateral condensation. J Endod 26: 748-750.

24. Deitch AK, Liewehre FR, West LA, Patton WR (2002) A comparison of fill density obtained by supplementing cold lateral condensation with ultrasonic condensation. J Endod 28: 665-667.

25. American Association of Endodontists (1994) Appropriateness of care and quality assurance guidelines. AAE, Chicago, USA.

26. Georgopoulou MK, Wu MK, Nikolaou A, Wesselink PR (1995) Effect of thickness on the sealing ability of some root canal sealers. Oral Surg Oral Med Oral Pathol Oral Radiol Endod 80: 338-344.

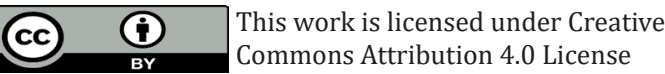

Submission Link: http://biomedres.us/submit-manuscript.php
27. Lee M, Winkler J, Hartwell G, Stewart J, Caine R (2009) Current trends in endodontic practice: emergency treatments and technological armamentarium. J Endod 35: 35-39.

28. Smith RS, Weller NR, Loushine RJ, Kimbrough WF (2000) Effect of varying the depth of heat application on the adaptability of gutta-percha during warm vertical compaction. J Endod 26: 668-672.

29. Wu MK, Van Der Sluis LWM, Wesselink PR (2002) A preliminary study of the percentage of gutta-percha-filled area in the apical canal filled with vertically compacted warm gutta-percha. Int Endod J 35: 527-535.

30. Kulid J, Lee C, Dryden J, Collins J, Feil F (2007) A comparison of five gutta percha obturation techniques to replicate canal defects. Oral Surg Oral Med Oral Path Oral Radiol Endod 103: 28-32.

\begin{tabular}{ll} 
BIOMEDICAL & Assets of Publishing with us \\
RESEARCHES & - Global archiving of articles \\
\hline & - Immediate, unrestricted online access \\
\hline
\end{tabular}

